\title{
Journal of Applied Sciences Research
}

\section{A Study on the Effects of Gas Nitriding on Aluminum 6061 for Automotive Engine Application}

\author{
${ }^{1}$ M. Faizairi M. Nor, ${ }^{2}$ Suhaimi Hassan, ${ }^{3}$ Kee Kok Eng, ${ }^{3}$ M. Azman Zakariya, ${ }^{3}$ Faizal Ahmad Fadzil, ${ }^{2}$ Kamal Ariff Zainal \\ Abidin, ${ }^{1 Z u l k i f l i ~ M . ~ R o s l i ~ a n d ~}{ }^{2}$ Jariah M. Juoi
}

${ }^{1}$ Institute of Transport Infrastructure, Universiti Teknologi PETRONAS (UTP), Perak, Mala

2Institute of Self Sustainable Building, Universiti Teknologi PETRONAS (UTP), Perak, Malaysia.

${ }^{3}$ Faculty of Manufacturing Engineering \& SM4GT of Advanced Manufacturing Centre, Universiti Teknikal Malaysia Melaka

Corresponding Author: Mohd Faizairi Mohd Nor, Institute of Transport Infrastructure, University of Technology PETRONAS, 32610, Seri Iskandar, Perak, Malaysia.

Tel: +605-3687153, Fax: +905-3656461, Hp: 012-6192899 E-mail: mfaizairi_mnor@utp.edu.my

Received date: 23 March 2018, Accepted date: 28 May 2018, Online date: 18 June 2018

Copyright: (C) 2018 Mohd Faizairi Mohd Nor, et al. This is an open-access article distributed under the terms of the Creative Commons Attribution License, which permits unrestricted use, distribution, and reproduction in any medium, provided the original author and source are credited.

\begin{abstract}
Aluminum start to replace cast iron in engine manufacturing due to its low weight but higher strength. This will produce high power-to-weight ratio engine. The problem is aluminum has low hardness and wears resistance. Cylinder wall tends to wear due to the reciprocating movement of piston inside during the engine operates and will lead to engine blow-by. Gas nitriding is one of the processes to increase those properties by forming aluminum nitride layer on it. This layer has high hardness and wears resistance.
\end{abstract}

Key words: Aluminum 6061, gas nitriding, micro-hardness test, scratch test, hardness test, wears resistance.

\section{INTRODUCTION}

Automotive cylinder is the main housing for hundreds of parts and contains cylinder space for piston, passaged for the coolant, exhaust and in take gases to pass over the engine and also host for crankcase and camshafts. As the demand increase, engine has transform drastically for better power, durability, resistance to wear and efficiency of the engine. At the early, engine block has been manufactured using cast iron alloy due to its high strength; low cost and high wear resistance. Then, aluminum alloys start to replace it due to low weight but has high strength and wear resistance. Cylinder liner acts as the passage for piston to move up and down during combustion process. It also exposed to high temperature and pressure during the operations. Piston, through the piston ring, in reciprocating motion, will come in contact directly with the inner surface of the cylinder liner thus promoting wears. Increasing the hardness will increase the wear resistance generally and these properties can be improved using many techniques and one of it is gas nitriding. Gas nitriding can be considered as simple and low cost process compare to other manufacturing methods. Furthermore, current technologies in preventing wears still have disadvantages.

\section{Literature Review:}

Manufacturers start to use aluminum alloy in engine making due to its low weight but still have higher strength [1]. Cylinder hole is the space for piston is travel up and down during the operation and exposed to wears [2]. Today, chrome plating is applied to protect the cylinder wall. But, once it damage, the whole block need to be replaced. The cast iron sleeve technique needs the hole is bored bigger than it should, and excess margin will be replaced using iron cast sleeve. But, it required lot of work, time and energy [3]. Aluminum 6061 is one of the most popular in 6000 series for medium to high strength requirements. It has excellent corrosion resistance to atmospheric, good corrosion resistance to saline environment, good finishing characteristic and responds well to anodizing [4] Nitriding is a thermochemical process in which the surface of the metal is added with nitrogen in to form nitride layer on the surface which has high hardness and wears resistance [5]. The process is carried out below the transformation temperature of the metal alloy [6]. Gas nitriding use ammonia ( $\mathrm{NH}_{3}$ ) gas. Ammonia will dissociate into nitrogen and hydrogen once it contacts the heated work piece. The nitrogen then diffuses onto the surface of the material creating nitride layer [2]. Nitriding an aluminum surface is very hard due to the thin oxide layer existing on the surface which keeps the dispersion of nitrogen into the aluminum substrate making it a slowly process [7]. Gas pressure did not have any significant effect to the thickness of layer as thickness remains constant if the gas pressure increases [8]. Aluminum has no diffusion zone like other metal [7]. Aluminum surface will change from metallic silver to dark gray or shiny black after nitriding due to the formation of aluminum nitride layer on the surface [9]. Aluminum nitride has high hardness (HV1400), high thermal conductivity and electrical resistivity. It has a hexagonal crystal structure and a covalent bonded material which required lot of energy to break it [10]. Conventional plasma nitriding of aluminum alloys conducted at temperature of $500^{\circ} \mathrm{C}$ for 20 hours form $5-10 \mu \mathrm{m}$ thick layers [11]. Scratch testing are used to determine the hardness of a material by scratches and abrasion. The scratcher will scratch the material with specific load on it and will result a track width [12]. Different hardness will have different width track and penetration depth. Hardness generally uses to determine wear resistance by measuring the resistance to plastic deformation. Increase in hardness will increase in wear resistance [6]. Wear usually result in progressive loss of material and wear coefficient is used to indicate the wear rate or quantify the material loss. High wear resistance material is indicating by how hard the material to be penetrate or loss by abrasion.

\section{Methodology:}

3.1 First Sample Preparation:

A 4"x4"x0.4" aluminum 6061 plate is cut using Electrical Discharge Machine (EDM) into 11 smalls 0.4 "x0.6"x0.4" block, 1 for base reading, 5 pieces for 4 hours and the rest for 8 hours gas nitriding process. All the samples then are grinded and polished until clean and smooth for even and strong coating. Grinding start with sand paper grit 180 followed by 400, 600, 800 and 1200. Then, the samples are polished using 6 micron and 1-micron diamond paste. All of these processes use 150rpm speed grinder and polisher. The final result must be smooth, even and mirror-finish. 


\subsection{Gas Nitriding:}

Firstly, samples are washed using $0.5 \mathrm{M}$ nitric acid before placed on tray and put inside the quartz tube furnace. Then, the tube is closed, sealed and turned on Purging is done during heat up by-passing nitrogen gas inside the tube to eliminate air from inside as the mixture of air and ammonia can cause explosion. Nitrogen will continue to flow until the furnace reach target temperature, $450^{\circ} \mathrm{C}$. After that, purging is stop and ammonia gas is flowed into the furnace at $10 \mathrm{~cm}^{3} / \mathrm{min}$. The temperature maintains at $450^{\circ} \mathrm{C}$ for 4 hours. Once the process is done, the flow of ammonia gas and furnace is turned off and the furnace undergoes purging again to eliminate ammonia from inside. Cooling will be done in nitrogen atmosphere to avoid discoloring by oxidation until reaching the room temperature. Then, the tube is opened, and sample is taken out. All of these steps are same for 8 hours gas nitriding.

Fig. 1: Gas Nitriding Process.

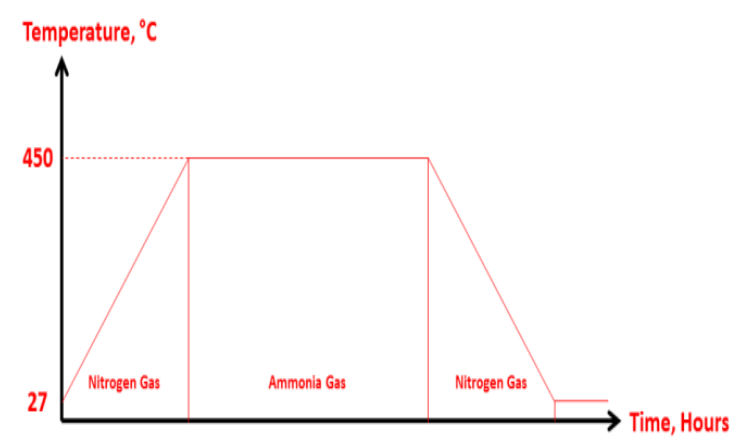

\subsection{Second Sample Preparation:}

The samples are cut into half using abrasive cutter. Then, it is mounted using hot mounting with inner cross section as the top side. After that, the samples are grinded using sand paper grit 180, 400, 600,800 and 1200 followed by polishing using 6 and 1-micron diamond paste until mirror finished. The mounted sample is washed using tap water followed by ethanol to remove excess water and left dried inside the dryer. Then, the sample is etched using Keller's etchant - a mixture of $190 \mathrm{ml}$ of distilled water, $5 \mathrm{ml}$ of nitric acid, $5 \mathrm{ml}$ of hydrochloric acid and $5 \mathrm{ml}$ of hydrofluoric acid by immersing it for 10 to 30 seconds. The surface must turn into matte grey. Etching is repeated until the whole surface turn matte. Lastly, the samples are washed again using tap water and ethanol and left dried under the dryer.

\subsection{Microstructure:}

Etched sample is placed on the sample holder and put inside the SEM chamber. The vacuum process is started. The SEM software is run. The coarse focus knob is adjusted slowly to magnify the microstructure until raw image can be seen. Then, the fine focus knob is adjusted to make the image clear. The adjusting process is stop when the desired structure can be seen clearly. The image can be seen at the monitor. Magnification is increased from 50x until 3000x. Then, the measurement for the layer thickness is taken. After that, the desired area for investigation is marked for built- in EDS inside SEM to compute the composition graph. Results can be interpreted from the graph produced.

\subsection{Hardness Test:}

The hardness test is conducted using the micro hardness Vickers machine. The machine is set up with 100gf load, 20 seconds dwell time and the indenter is diamond shape stylus. The sample is placed under the lens with 100x magnification. The main focus knob is adjusted until the image is clear. When everything is ready, the machine is started. The value for $\mathrm{D}_{1}$ and $\mathrm{D}_{2}$ of the indentation is measured using special eyepiece. The $\mathrm{HV}$ value will be generated by the machine. Ten readings are taken and recorded from each sample and then the average value is calculated.

\subsection{Scratch Test:}

The scratch test is conducted using the Revetest Scratch Tester. Firstly, the sample is placed under the indenter. The indenter is adjusted so it will touch the sample without apply any load yet. The machined is start and set up with $5 \mathrm{~N}$ constant load, $5 \mathrm{~mm} / \mathrm{min}$ speed and track distance is $5 \mathrm{~mm}$. The indenter is $200 \mu \mathrm{m}$ spherical diamond stylus. The machine is run to scratch. Each surface must be scratched at least 3 times with each line is a track length far to each other. Each line is measured at least at 3 points for the width track and recorded. Then, the total average is calculated.

\section{RESULTS AND DISCUSSION}

\subsection{Gas Nitriding:}

Fig. 2: Unnitrided sample.

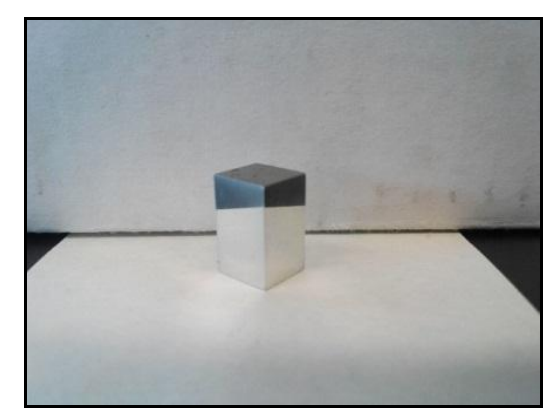

Unnitrided sample has mirror surface as shown in Figure 2 and act as base. Figure 3 shows the 4 hours samples that turns from the shiny mirror surface into semi-matte grey color. Figure 4 shows the 8 hours samples turn completely into matte grey color. All of these changes observed after being nitrided at $450^{\circ} \mathrm{C}$. This change is due to the formation of layer on the surface. As ammonia flow into the furnace, it will dissociate into hydrogen and nitrogen gas. Nitrogen gas will diffuse into the aluminum surface and form black aluminum nitride layer. This layer will form evenly along the surface and cover the mirror surface. As time increase, more aluminum nitride form thus covers the mirror surface completely. 
Citation: M. Faizairi M. Nor, et al., 2018. A Study on the Effects of Gas Nitriding on Aluminum 6061 for Automotive Engine Application. Journal of Applied Sciences Research., 14(3): 6-12.

Fig. 3: 4 hours nitrided sample.
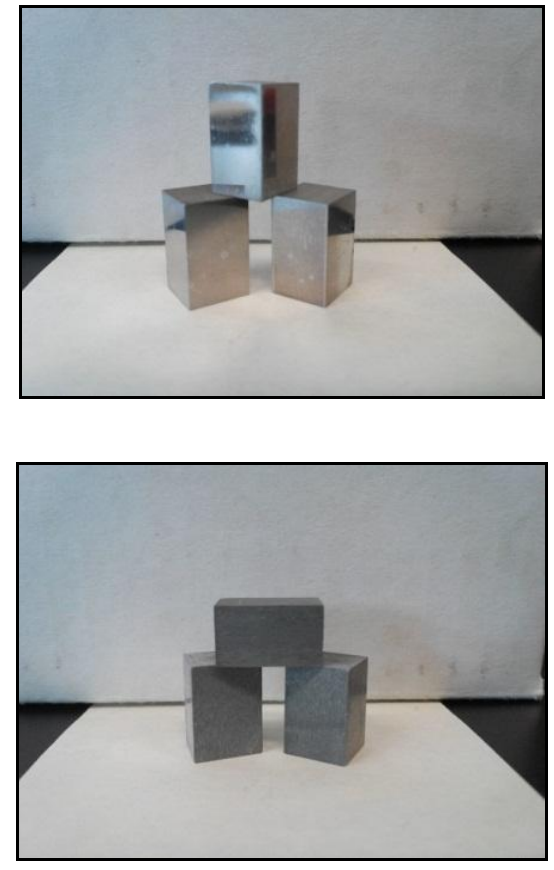

Fig. 4: 8 hours nitrided sample.

\subsection{Microstructure:}

Unnitrided sample show no formation of layer under the OM. Oxide layer also cannot be seen. Figure 5 shows 4 hours sample with formation of thin layer on it while 8 hours sample shows even thicker layer compare to 4 hours sample as shown in Figure 6 . Using the OM, 4 hours sample has approximately $3 \mu \mathrm{m}$ layer thickness and 8 hours sample has $6 \mu \mathrm{m}$ layer thickness. By using the SEM, the layer on 4 hours sample is $1.3 \mu \mathrm{m}$ while 8 hours sample has $3 \mu \mathrm{m}$ layer in thickness. EDS is used to determine the composition of the black layer (Point 1) and the area below it (Point 2). This is confirmed whether the black layer is aluminum nitride compound or not.

Fig. 5: 4 hours sample under SEM.
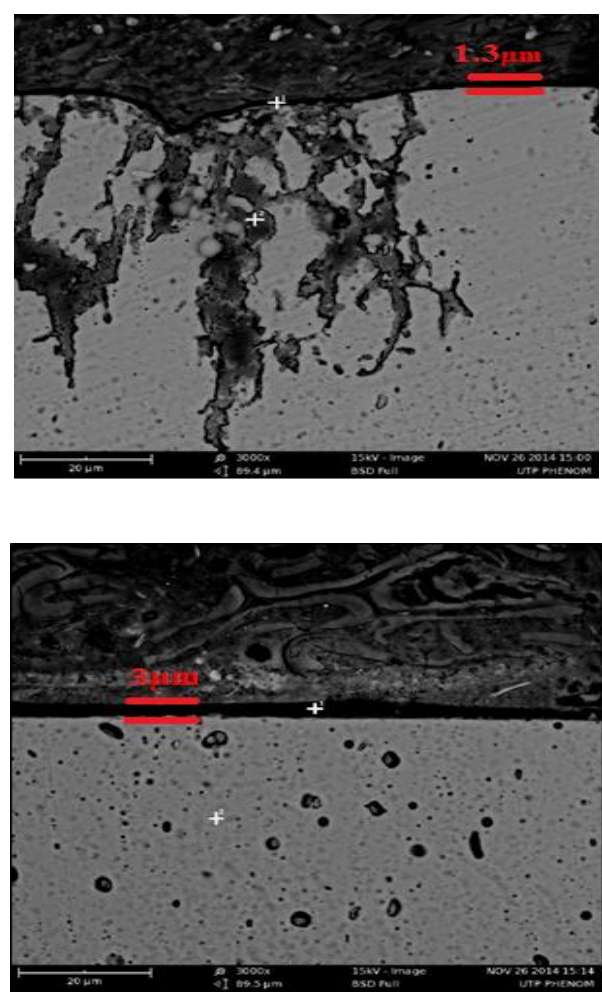

Fig. 6: 8 hours sample under SEM.

The composition graphs generated by the EDS show the elements can be found on the layer. High peak of aluminum and nitrogen indicates that the layer is aluminum nitride. High peak of aluminum with low and almost equal peak of other element such as oxygen, silicon and magnesium indicate the area below the black layer is just a normal aluminum 6061 substrate. As time increase, more aluminum nitride form on the surface due to constant supply of nitrogen gas. Thus, the layer becomes thicker. Aluminum however do not have diffusion zone since it has very low solubility due its FCC structure. 


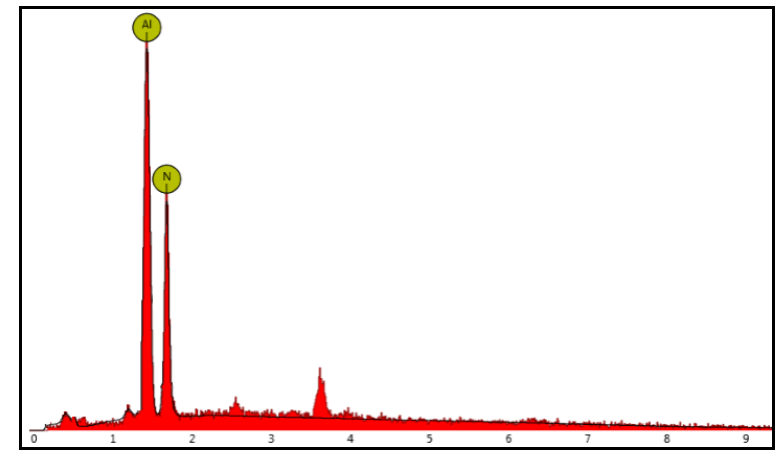

Fig. 7: EDS for 4 hours sample on the layer (Point1).

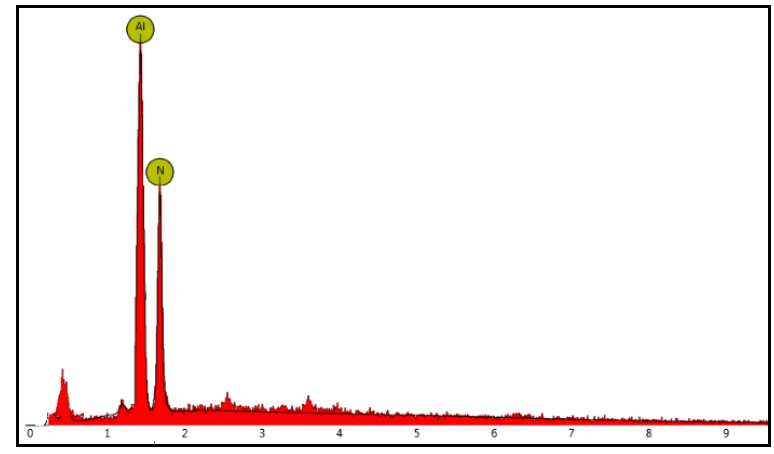

Fig. 8: EDS for 8 hours sample on the layer (Point 1).

\subsection{Hardness Test:}

The average hardness for unnitrided sample is HV96 as shown in Table 1. This is equal to the theoretical hardness value for aluminum 6061 which is HV96 to HV98. Table 2 shows the hardness readings taken from the Aluminum 6061 surface after being nitrided at $450^{\circ} \mathrm{C}$ for 4 hours. The average hardness is HV114. There is increase in hardness about $18 \%$ compare to the unnitrided sample hardness. Table 3 shows the hardness reading taken from the Aluminum 6061 surface after being nitrided at $450^{\circ} \mathrm{C}$ for 8 hours. The average hardness is HV123. There is increase in hardness around $28 \%$ from the unnitrided sample hardness and $8 \%$ compare to the 4 hours nitrided sample. Aluminum nitride has HCP crystal structure, a very pack structure with 6 atoms per unit cell. Deformation of material due to dislocation of the grains and grain boundaries will stop the dislocations. As the grain too tight to move and slip on each other, only small dislocation is occur making the material very hard to deform and brittle.

Table 1: HV value for unnitrided sample.

\begin{tabular}{|c|c|c|}
\hline \multirow{2}{*}{ UNNITRIDED } & 97 & 94 \\
\cline { 2 - 3 } SAMPLE & 94 & 96 \\
\cline { 2 - 3 } & 96 & 95 \\
\cline { 2 - 3 } & 95 & 99 \\
\cline { 2 - 3 } AVERAGE & 97 & 97 \\
\hline READING & \multicolumn{2}{|c|}{96} \\
\hline
\end{tabular}

Table 2: HV value for 4 hours sample.

\begin{tabular}{|c|c|c|}
\hline \multirow{2}{*}{ NITRIDED } & 115 & 115 \\
\cline { 2 - 3 } SAMPLE & 111 & 113 \\
\cline { 2 - 3 } 4 HOURS & 116 & 112 \\
\cline { 2 - 3 } $450^{\circ} \mathrm{C}$ & 117 & 116 \\
\cline { 2 - 3 } & 113 & 114 \\
\hline AVERAGE & \multicolumn{2}{|c|}{114} \\
READING & \multicolumn{2}{|c|}{} \\
\hline
\end{tabular}

Table 3: HV value for 8 hours sample.

\begin{tabular}{|c|c|c|}
\hline \multirow{2}{*}{ NITRIDED } & 121 & 124 \\
\cline { 2 - 3 } SAMPLE & 123 & 123 \\
\cline { 2 - 3 } 8 HOURS & 121 & 124 \\
\cline { 2 - 3 } $450^{\circ} \mathrm{C}$ & 122 & 121 \\
\cline { 2 - 3 } & 125 & 123 \\
\hline AVERAGE & \multicolumn{2}{|c|}{123} \\
READING & \multicolumn{2}{|c|}{} \\
\hline
\end{tabular}


4.4 Scratch Test:

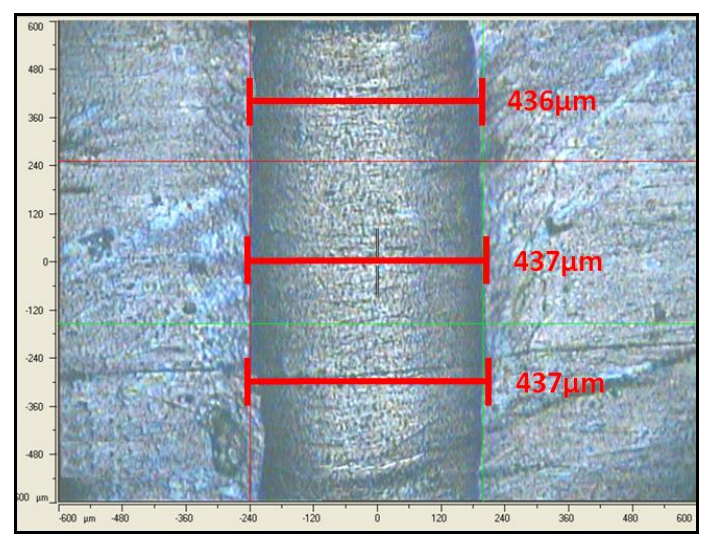

Fig. 9: Scratch track for unnitrided sample.

Figure 9 shows the scratch track on unnitrided sample. The width of the track was measure at three points for each line. There are total of 9 readings and the average width track for unnitrided sample is $436 \mu \mathrm{m}$.

Fig. 10: Scratch track for 4 hours sample.

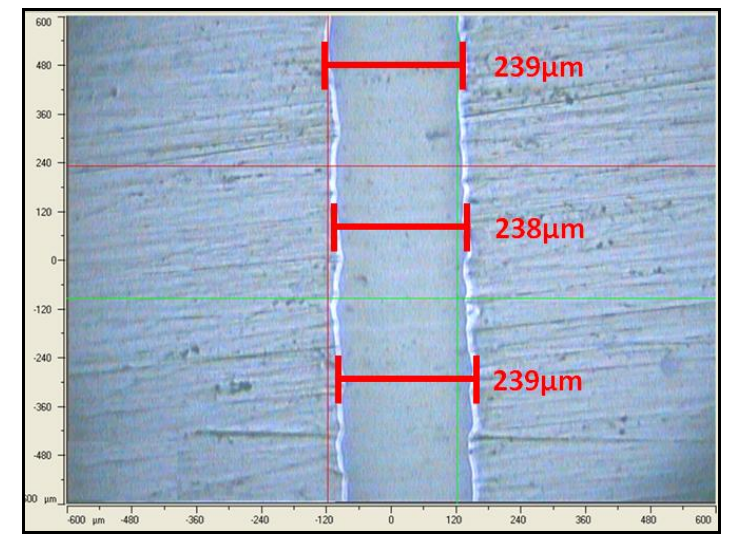

Figure 10 shows the scratch track on 4 hours at $450^{\circ} \mathrm{C}$ nitrided sample. The width track is smaller compare to unnitrided sample with the average width is $239 \mu \mathrm{m}$.

Fig. 11: Scratch track for 8 hours sample.

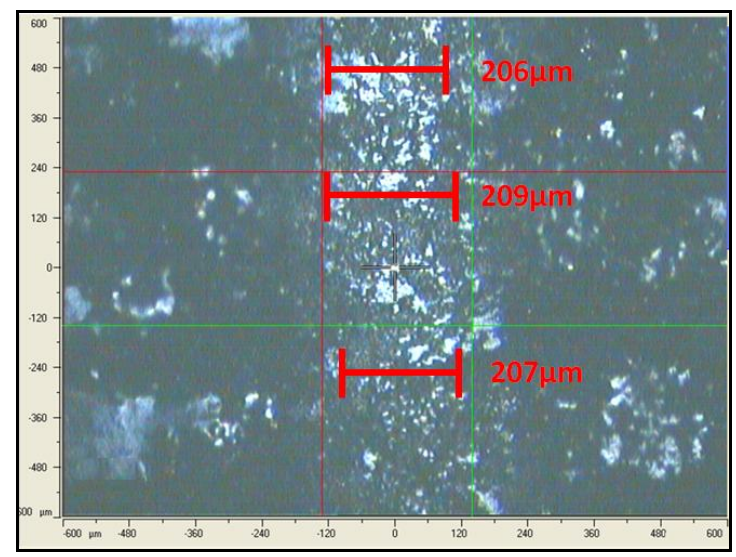

Figure 11 shows the scratch track on 8 hours at $450^{\circ} \mathrm{C}$ nitrided sample which is barely to see. It is smaller compare to unnitrided and 4 hours sample. The average width is $207 \mu \mathrm{m}$.

From Figure 12, the graph shows that the penetration depth on unnitrided sample is $96 \mu \mathrm{m}$.

Figure 13 shows the penetration depth for the 4 hours nitrided sample. The penetration depth is $40 \mu \mathrm{m}, 55 \%$ shallower compare to unnitrided sample.

Figure 14 shows the penetration depth on 8 hours at $450^{\circ} \mathrm{C}$ nitrided sample. The penetration depth is $26 \mu \mathrm{m}$ which is $73 \%$ shallower compare to unnitrided sample and $35 \%$ shallower than 4 hours nitrided sample. These indicate that 8 hours sample is the hardest to scratch and penetrate compare to others sample. Scratch hardness number is then calculated using the formula below.

$H S_{p}=\frac{8 P}{\pi w^{2}}$

Where $\mathrm{P}$ is normal force applied and $\mathrm{w}$ is the average width track in meter. 
Citation: M. Faizairi M. Nor, et al., 2018. A Study on the Effects of Gas Nitriding on Aluminum 6061 for Automotive Engine Application. Journal of Applied Sciences Research., 14(3): 6-12.

Table 4: Scratch hardness number.

Table 4: Scratch hardness number.
\begin{tabular}{|l|l|}
\hline Sample & $\boldsymbol{H S}_{\boldsymbol{P}}$ \\
& ${ }_{(\mathrm{GPa})}$ \\
\hline Unnitrided & 0.07 \\
\hline 4 hours & 0.22 \\
\hline 8 hours & 0.3 \\
\hline
\end{tabular}

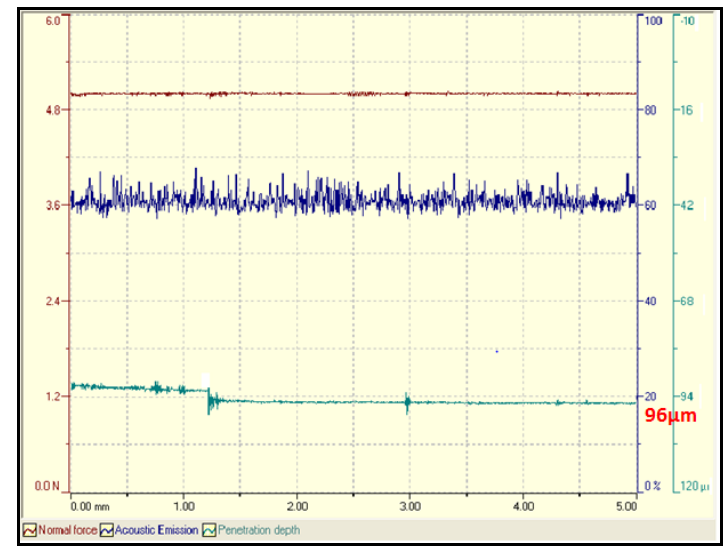

Fig. 12: Penetration depth for unnitrided sample.

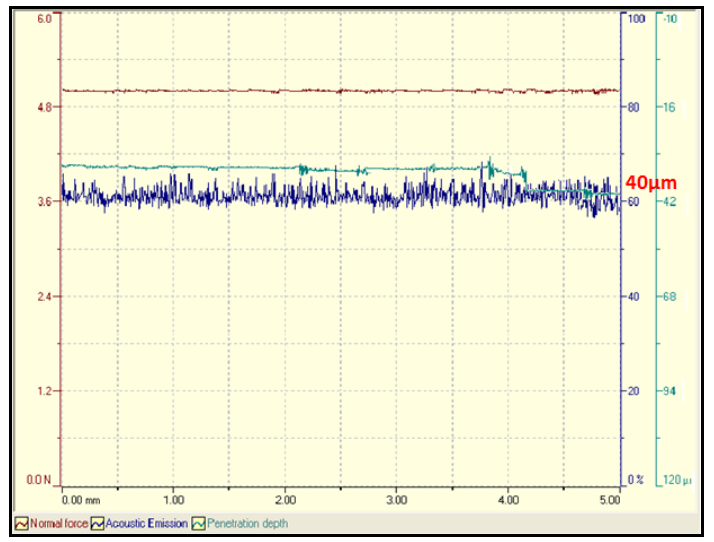

Fig. 13: Penetration depth for 4 hours sample.

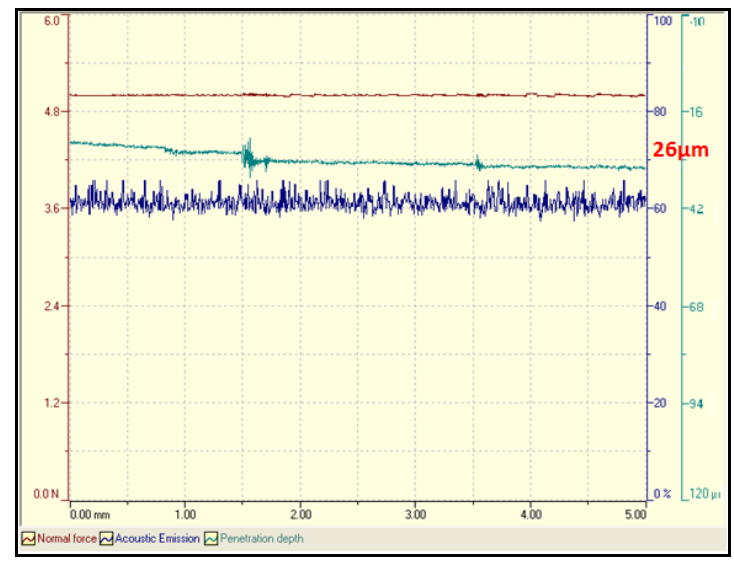

Fig. 14: Penetration depth for 8 hours sample.

High hardness properties making aluminum nitride is hard to scratch and penetrate. This property reduces the chances for aluminum nitride to lose its quantity and dimension when force is applied repeatedly on it and also prevent it from deform. In other words, as the hardness of material increase, it is become harder to scratch and penetrate, thus tendency of it to lose its quantity also decrease. Even though the mechanical property such as scratch hardness number does not has any correlation to wear rate, the quantification of wear debris produced after the scratch test is related to the wear performance. High amount of debris produced indicates the low wear resistance of the material. Width of the scratch track is using to determine the scratch hardness number but this track does not necessarily form when the material wear. Thus, the wear debris that produced during the scratch test is the real indicator for wear performance and this property must give prioritized while using scratch test abrasive wear.

\section{Recommendation}

Sample preparation is very important before conducting the gas nitriding process. Sample must be even, smooth and mirror finish. This can be obtaining through grinding and polishing process. Sample then must be washed using ethanol and nitric acid before putting into the furnace to remove any debris and any 
contamination. This is also functioning to remove the oxide layer. Purging must be done before ammonia is flow in to prevent explosion. Ammonia gas can be flow in once air percentage drop to $10 \%$. Then, once the process is done, purging must be done once again during cooling to prevent the samples from oxidized.

\section{CONCLUSION}

All objectives were achieved. The gas nitriding was successfully conducted on aluminum 6061 at $450^{\circ} \mathrm{C}$ for 4 and 8 hours. The microstructure inspection using OM shows that there are formation of black layer on both 4 and 8 hours samples. The close-up view and composition inspection using SEM and EDS confirm that the layer is nitride layer. The layer thickness for 8 hours sample is thicker than 4 hours sample. Hardness test shows that 4 hours sample is harder than unnitrided sample and 8 hours sample is hardest compare to unnitrided and 4 hours sample. The scratch test showing significance results in hardness and wear performance. The width track for 4 hours sample is smaller than unnitrided sample. 8 hours sample has the smallest width track among those three samples. This penetration depth also depicts the same result. 4 hours sample has shallow penetration depth compare to unnitrided sample. 8 hours sample has the shallow penetration depth. All of these significant results indicate that nitrided sample has better hardness and wear resistance compare to unnitrided sample. Among the nitrided samples, 8 hours sample has the best hardness and wear performance. Both 4 hours and 8 hours sample has high hardness compare to the AA 319 and this too includes the wear performance. The gas nitriding process produced $3 \mu \mathrm{m}$ nitride layer per side making it increase the original diameter as much as $6 \mu \mathrm{m}$. This is acceptable since the clearance gap is $\pm 20 \mu \mathrm{m}$.

\section{REFERENCES}

[1] Nguyen, H., 2005. Manufacturing Process and Engineering Material Used in Automotive Engine Blocks. School of Engineering Grand Valley State University.

[2] Rao, K.S., R.G. Chandra, K. Dinesh, 2013. Improvement of wear resistance in engine cylinder liner using gas nitriding. International Journal of Engineering and Innovative Technology, 55-57.

[3] Schueneman, T. (n.d.), 2014. Cylinder plating VS Cylinder sleeves. Retrieved December 18, 2014, from http://www.kenoconnorracing.com/Cylinder plating VS Cylinder Sleeves.html.

[4] Extruded Aluminum Alloy, 2010. Retrieved November 5, 2013, from http://www.sapagroup.com/pages/522574/Brochures/Sapa Alloy 6061.pdf.

[5] Yang, M., 2012. Nitriding - Fundamentals, modeling and process optimization. Worcester Polytechnic Institute.

[6] The Materials Information Society. ASM International, 2003. Practical Nitriding and Ferritic Nitrocarburizing. Chapter 1: An Introduction to Nitriding.

[7] Okumiya, M., M. Yoshida, R. Ichiki, C. Tekmen, W. Khalifa, Y. Tsunekawa, K. Tanaka, 2009. Surface Modification of Aluminum Using a Combined Technique of Barrel Nitriding and Plasma Nitriding. Plasma Processes and Polymers, 6: S287-S290.

[8] Yoshida, M., M. Okumiya, R. Ichiki, C. Tekmen, W. Khalifa, Y. Tsunekawa, T. Hara, 2009. A Novel Method for The Production of AlN Film with High Adhesion on Al Substrate. Journal of Plasma and Fusion Research SERIES, 8: 1447-1450.

[9] Visuttipitukul, P., T. Aizawa, H. Kuwahara, 2001. Surface modification of in-process refined aluminum alloy by morphology-free processing. Journal of Advanced Science, 13(3): 317-320.

[10] Adams, M., 2013. Aluminum Nitride, AIN Ceramic Properties. Retrieved December 25, 2014, from http://accuratus.com/alumni.html.

[11] Czerwinski, F., 2013. Thermochemical Treatment of Metals. In Heat Treatment - Conventional and Novel Applications (1st ed., 1: 73). In Tech.

[12] Lubrication Engineers Incorporation, 2010. Piston ring and cylinder wear and failures. Techni/Tips - A publication of the Lubrication Engineers Technical Department. (72). Retrieved from http://www.le-international.com/technical-information.html. 